\title{
Immunoreactive Apolipoprotein E is a Widely Distributed Cellular Protein Immunohistochemical Localization of Apolipoprotein E in Baboon Tissues
}

Chin-Tarng Lin, Yufang $X u$, Jang-Yen Wu, and Lawrence Chan*

Department of Physiology, The Milton S. Hershey Medical Center, Hershey, Pennsylvania 17033;

*Departments of Cell Biology and Medicine, Baylor College of Medicine, Houston, Texas 77030

\begin{abstract}
Apolipoprotein (apo) $E$ is an important protein determinant in cholesterol homeostasis in man. The protein is synthesized by the liver as well as by a number of extrahepatic tissues. In the present study, immunohistochemical techniques were used to identify apoE in specific cells in various baboon organs. In the 11 tissues studied, the following cell types have been found to harbor apoE immunoreactivity: cerebral astrocytes; thyroid follicular cells; alveolar type II pneumocytes; hepatocytes, and Kupffer cells; adrenocortical cells in zona fasciculata and zona reticularis; adrenal medullary cells; some renal tubular epithelia; some pancreatic islet cells; histiocytic macrophages in lymph nodes and the spleen; some gastric mucosal epithelia; and ovarian occytes. These observations indicate the wide distribution of apoE in many organs and suggest that the protein might perform other important functions such as regulation of local hormonal homeostasis in addition to its role in cholesterol metabolism.
\end{abstract}

\section{Introduction}

Apolipoprotein $\mathrm{E}(\mathrm{apoE})^{1}$ is a major apolipoprotein found in plasma chylomicrons, chylomicron remnants, very low density lipoprotein, and high density lipoprotein, in man and in other mammalian species $(1,2)$. Rall et al. (3) have reported the complete amino acid sequence of apoE. It is a 299-residue polypeptide of $34,000 \mathrm{D}$. ApoE plays an important role in cholesterol metabolism as a recognition signal for the receptor-mediated hepatic removal of cholesterol-laden HDL and chylomicron remnants from the circulation $(1,2,4-6)$. It binds to the low density lipoprotein receptor of various cells and tissues. It also binds to a specific apoE receptor in the liver and mediates the hepatic uptake of chylomicron remnants. In this way, apoE appears to function in the movement of cholesterol from peripheral tissues to the liver for metabolism and elimination $(1,2,5,6)$.

Address reprint requests to Dr. Lin, Department of Physiology, the Milton S. Hershey Medical Center, Pennsylvania State University, Hershey, PA 17033.

Received for publication 13 December 1985 and in revised form 2 June 1986.

1. Abbreviations used in this paper: $\mathrm{ABC}$, avidin-biotin peroxidase complex; apoE, apolipoprotein E; PAP, peroxidase-antiperoxidase complex; PBSC, $0.1 \%$ phosphate buffer containing $8.5 \%$ sucrose and $0.002 \% \mathrm{CaCl}_{2}$; SDS-PAGE, sodium dodecyl sulfate-polyacrylamide gel electrophoresis.

J. Clin. Invest.

(c) The American Society for Clinical Investigation, Inc. $0021-9738 / 86 / 10 / 0947 / 12 \quad \$ 1.00$

Volume 78, October 1986, 947-958
In the rat, the liver, and to a much lesser extent, the small intestine appear to be the major sources of plasma apoE (7-9). Furthermore, the rate of apoE synthesis in these organs was modulated by dietary manipulations in this animal (7-9). Basu et al. $(10,11)$ first reported that mouse peritoneal macrophages as well as cultured human monocytes synthesized the protein;

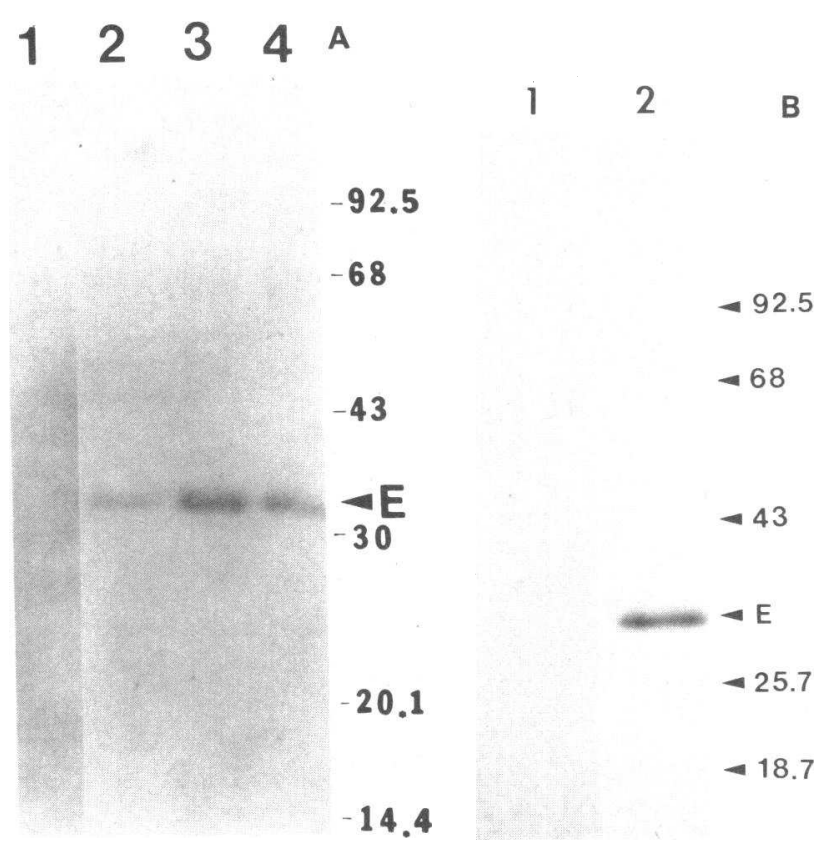

Figure 1. $(\dot{A})$ Immunoblot of baboon serum and human and baboon VLDL apoproteins against apoE antiserum. Baboon serum (lanes 1 and 2), VLDL apoproteins (lane 3) and human VLDL apoproteins (lane 4) were electrophoresed on a $10 \%$ SDS-polyacrylamide slab gel and electrophoretically transferred to a nitrocellulose paper. Lanes 2-4 were then stained with anti-human apoE and lane 1 was stained with preimmune serum using the immunoperoxidase technique (20). A single band of $\sim 34 \mathrm{kD}$ is seen in lanes $2-4$, but lane 1 shows no specific band. (B) Fluorograph of immunoprecipitated translation product. PolyA RNA from baboon liver was translated in vitro in a reticulocyte lysate system using $\left[{ }^{35} \mathrm{~S}\right] \mathrm{Met}$ as a precursor. ApoE immunoreactive product was precipitated by a rabbit anti-human antiserum, and the immunoprecipitated product was analyzed on a $10 \%$ polyacrylamide slab gel in SDS. The gel was processed for fluorography, and then exposed to (Kodak XS-1, Eastman Kodak Co., Rochester, NY) film for $40 \mathrm{~h}$. (Lane 1) immunoprecipitation performed in the presence of excess purified human apoE. (Lane 2) immunoprecipitation under normal conditions (17). In each case, $2 \mu \mathrm{g}$ of RNA were used. Molecular mass standards used were phosphorylase $\mathrm{B}, 92.5 \mathrm{kD}$; bovine serum albumin, $68 \mathrm{kD}$; ovalbumin, $43 \mathrm{kD}$; carbonic anhydrase, $30 \mathrm{kD}$; $\alpha$-chymotrypsinogen $25.7 \mathrm{kD}$; soybean trypsin inhibitor, $20.1 \mathrm{kD}$; $\beta$-lactoglobulin, $18.4 \mathrm{kD} ; \alpha$-lactalbumin, $14.4 \mathrm{kD}$. E signifies the position of migration of human apoE protein. 

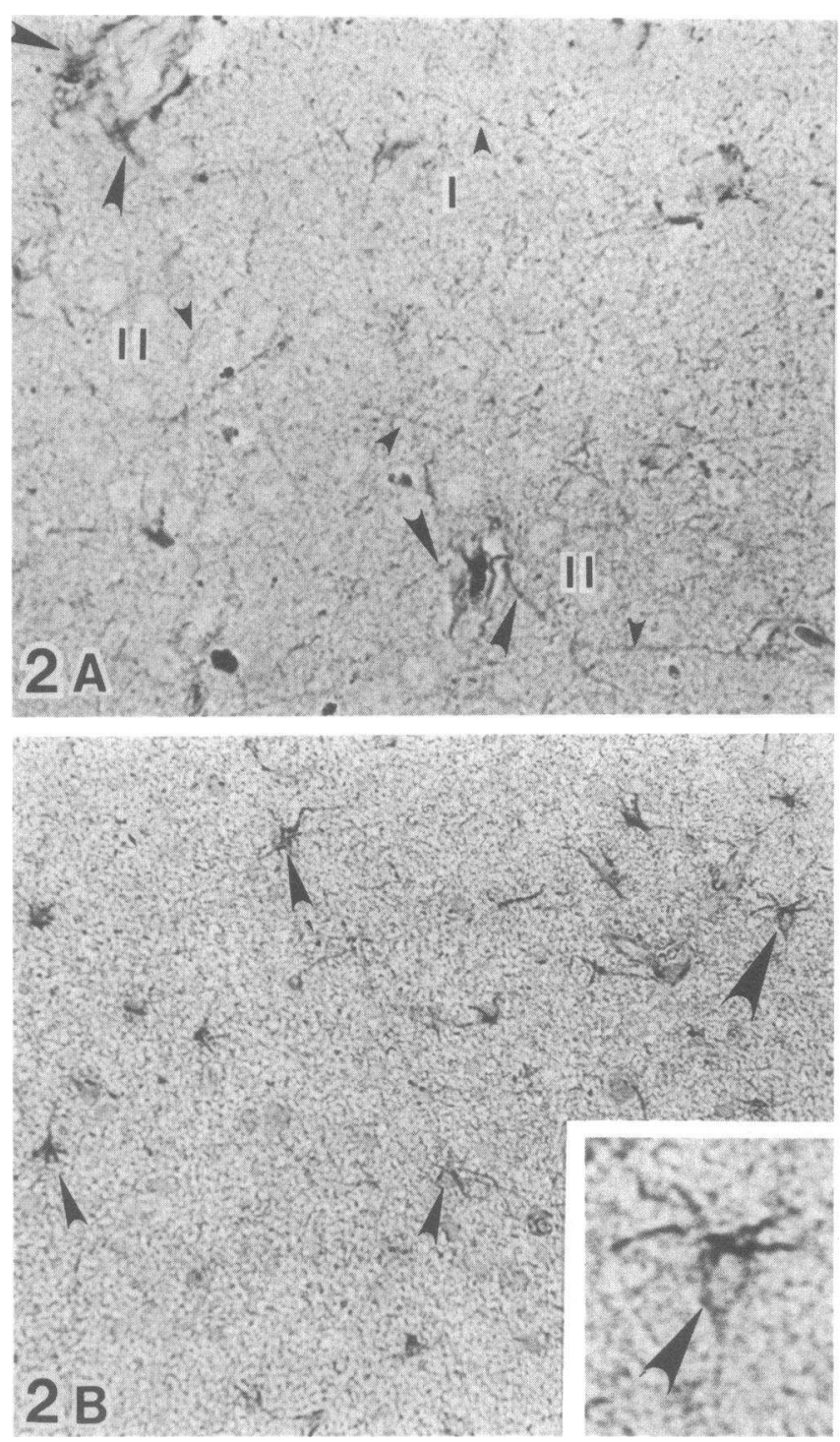

Figure 2. Immunohistochemical localization of apoE in the frontal lobe of the baboon cerebral cortex. $(A)$ Cerebral cortex layer I (I), and layer II (II). Immunoreactive apoE reaction products are seen mainly in intermingled astrocytic glia processes (small arrowheads). Some stained astrocytic processes ending on two small vascular walls (large arrowheads) are also shown. $(\times 600)$. (B) Cerebral white matter. Most astrocytic glial cell bodies and their processes are stained (large and small arrowheads). (× 600). (Inset) A high magnification taken from the area marked by the large arrowhead. Peroxidase reaction product

and Blue et al. (12) showed that apoE is also synthesized by human kidney and adrenal gland. Recently, a number of other laboratories (13-18) have independently reported that mammalian liver, adrenal, testis, ovary, lung, spleen, mesenteric lymph node, heart, aorta, kidney, thymus, brain, and small intestine all synthesize apoE in organ culture in vitro, or contain apoE messenger (m)RNA as measured by translation in vitro or by nucleic acid hybridization to cloned apoE complementary (c)DNA probes. Since these organs contain diverse cell types, we have undertaken a study to localize apoE in the cells in many
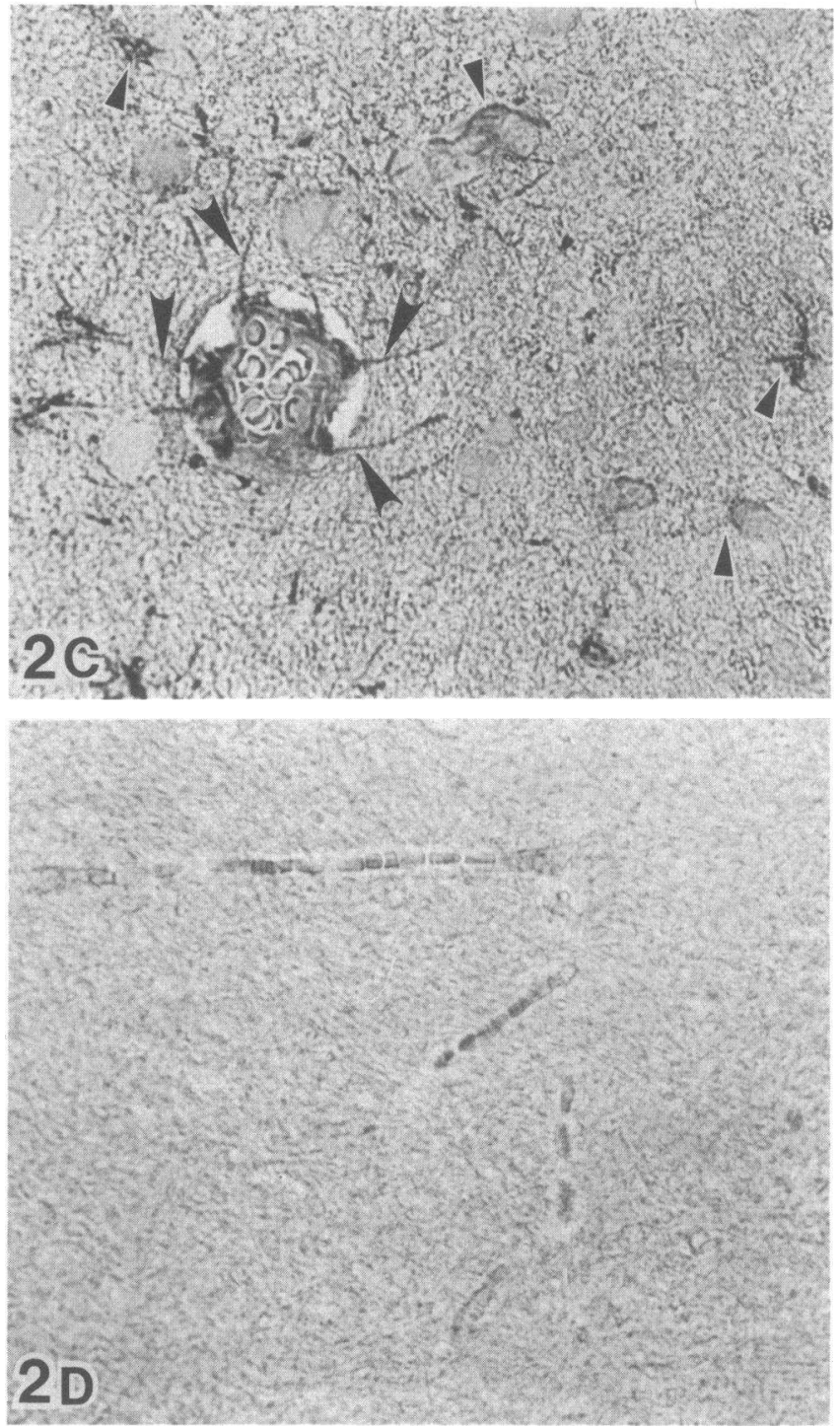

is detected in the astrocytic cell body (arrowhead) and along its processes $(\times 1,800)$. $(C)$ A higher magnification taken from the cerebral white matter. The stained astrocytic processes are seen clearly ending on one small blood vessel (black arrowheads). Other glial cells are also stained (black and white arrowheads). $(\times 1,200)$. (D) A control section taken from cerebral white matter and stained with preimmune serum shows no specific glial staining. Note that some erythrocytes in three capillaries show weak staining due to the endogenous peroxidase-like activity of hemoglobin $(\times 600)$.

of the organs that synthesize apoE. We report our results on the immunohistochemical localization of apoE in various baboon organs including the cerebral cortex, thyroid, lung, liver, adrenal, kidney, pancreas, spleen, mesenteric lymph node, ovary, and stomach. Our observations indicate that while apoE is widely distributed, the protein is only detected in specific types of cells in various organs and tissues. We speculate that apoE might perform some as yet unidentified but potentially important functions in many of the highly specialized cells in which they are found. 


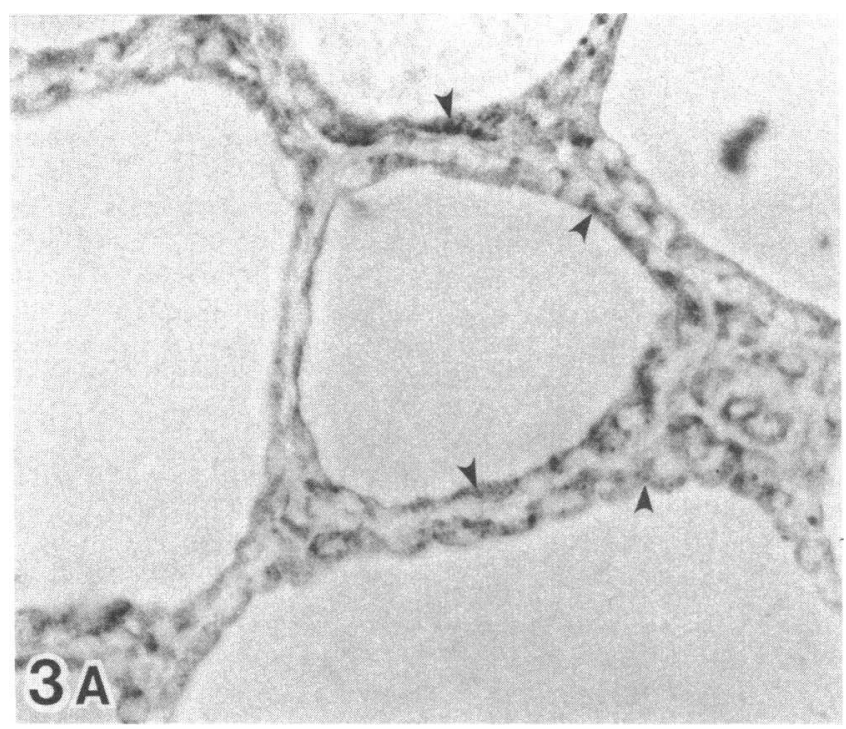

Figure 3. Immunohistochemical staining of apoE in the thyroid gland. (A) Granular reaction products are seen distributed throughout the cytoplasm of the follicular epithelia. Some epithelial cells contain more reaction products than others. The interstitial space and their cellular

\section{Methods}

Characterization of rabbit antibodies against human baboon apoE. A rabbit antiserum against purified human apoE was used in these studies. The details of the antibody production have been published (19). The antibody is monospecific against human apoE, and does not react against other human apolipoproteins or serum albumin. It crossreacts well with baboon apoE (see Results).

Immunohistochemistry. Because the rabbit antiserum against human apoE crossreacts with baboon apoE, this antiserum was used in our immunohistochemical studies. Tissues were obtained from three normal adult female baboons. The procedure for immunohistochemistry was the same as described previously (20-23) with some modifications. In brief, for tissue preparations, after the baboon was anesthetized, tissue fragments from cerebral frontal cortex and visceral organs including thyroid, liver, kidney, pancreas, spleen, mesenteric lymph node, stomach, lung, ovary, and adrenal were immersed immediately in $4 \%$ paraformaldehyde or a mixture of $4 \%$ paraformaldehyde and $0.1 \%$ glutaraldehyde in $0.1 \%$ phosphate buffer, $\mathrm{pH} 7.4$, containing $8.5 \%$ sucrose and $0.002 \%$ $\mathrm{CaCl}_{2}$ (PBSC) for $96 \mathrm{~h}$. Tissue fragments were then washed in PBSC twice, 10 min each, immersed in $0.025 \mathrm{M}$ hydroxylamine in PBSC for 30 min to block excess aldehyde groups, dehydrated in ethanol, embedded in paraffin blocks, cut at $5-\mu \mathrm{m}$ thickness, mounted on the glass slides, and incubated at $57^{\circ} \mathrm{C}$ overnight. For immunostaining, the tissue slides were deparaffinized in xylene and toluene and replaced in $100 \%$ ethanol. The slides were then incubated in absolute methanol containing $1 \% \mathrm{H}_{2} \mathrm{O}_{2}$ for 10 min to block endogenous peroxidase activity and rehydrated sequentially in $95 \%$ ethanol, then 90,75 , and $50 \%$ ethanol. After rinsing in PBSC, tissue sections were incubated with $0.05 \%$ pronase in distilled water for $2.5 \mathrm{~min}$ to reduce background staining, then washed in PBSC twice, 10 min each, and finally coated with normal goat serum (at 1:40 dilution) for $10 \mathrm{~min}$ and incubated with rabbit antiserum against human apoE for $2 \mathrm{~h}$ at 1:50 dilution or overnight at 1:200 dilution.

Tissue slides were washed twice, for $10 \mathrm{~min}$ each time, incubated with biotinylated second antibodies (Vector Laboratories, Burlingame, CA) at 1:200 dilution for $1 \mathrm{~h}$, rewashed in PBSC, and finally incubated for $30 \mathrm{~min}$ with avidin-biotin peroxidase complex (ABC) (Vector Laboratories). The ratio of avidin to biotinylated peroxidase was $5: 2$. For

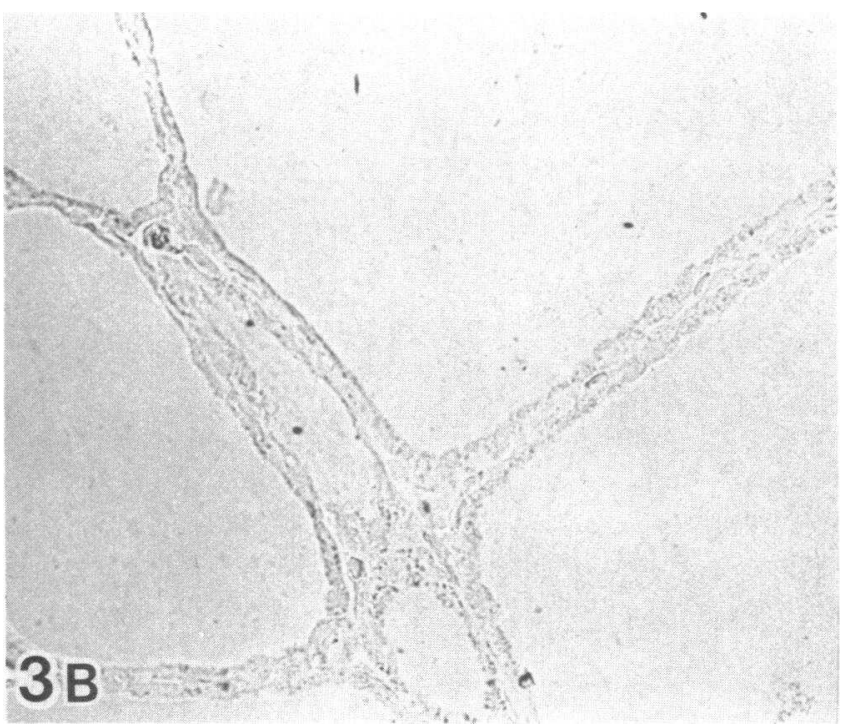

elements are not stained. The colloid substance in each follicle is also unstained $(\times 1,500)$. $(B)$ A control section stained with antiserum against ovalbumin shows no reaction product $(\times 1,500)$.

sections of the stomach, the following modification was introduced because the gastrointestinal tract contained endogenous biotin. The gastric tissue section was incubated with peroxidase-labeled second antibody at 1:200 dilution (Miles Chemicals, Naperville, IL) for $60 \mathrm{~min}$. After washing, the section was further incubated with peroxidase antiperoxidase complex (Miles Chemicals) at 1:80 dilution for $15 \mathrm{~min}$ to replace the avidin-biotin complex (22) or $\mathrm{ABC}$ system. Thereafter, the procedure used was the same as the $A B C$ method.

After additional washing in PBSC for 10 min twice, sections were fixed in $2.5 \%$ glutaraldehyde for $5 \mathrm{~min}$ and incubated with $0.05 \% 3,3^{\prime}$ diaminobenzidine $4 \mathrm{HCl}$ in $0.2 \mathrm{M}$ Tris- $\mathrm{HCl}$ buffer, $\mathrm{pH} 7.2$, plus $0.005 \%$ $\mathrm{H}_{2} \mathrm{O}_{2}$ for $5 \mathrm{~min}$. They were then washed in PBSC and refixed in $0.01 \%$ $\mathrm{OsO}_{4}$ for $30 \mathrm{~s}$. After rinsing in water, they were mounted in $50 \%$ glycerine in phosphate buffer. The slides were sealed with fingernail polish and observed under the light microscope.

For control experiments, some sections were incubated with normal rabbit serum instead of the specific antiserum; other sections were incubated with rabbit antiserum against ovalbumin or with antiserum against apoE that had been previously adsorbed with excess purified human apoE. All three controls were included in each of the tissues studied.

\section{Results}

Reactivity of anti-human apoE serum against baboon apoE. To test the reactivity of the rabbit antiserum against baboon apoE, human very low density lipoprotein (VLDL), baboon serum and baboon VLDL apoproteins were fractionated in 10\% SDSpolyacrylamide gel electrophoresis (PAGE) and electrophoretically transferred to a nitrocellulose paper. The immunoblot was stained with rabbit anti-human apoE or with preimmune serum using the immunoperoxidase technique (20) (Fig. $1 \mathrm{~A}$ ). A single band was detected in both the human and the baboon samples (Fig. 1 $A$, lanes 2-4). Addition of excess purified human apoE abolished all three bands (data not shown), and incubation with preimmune serum did not reveal any specific band (Fig. $1 \mathrm{~A}$, lane 1). Translation of baboon liver RNA in vitro was performed 

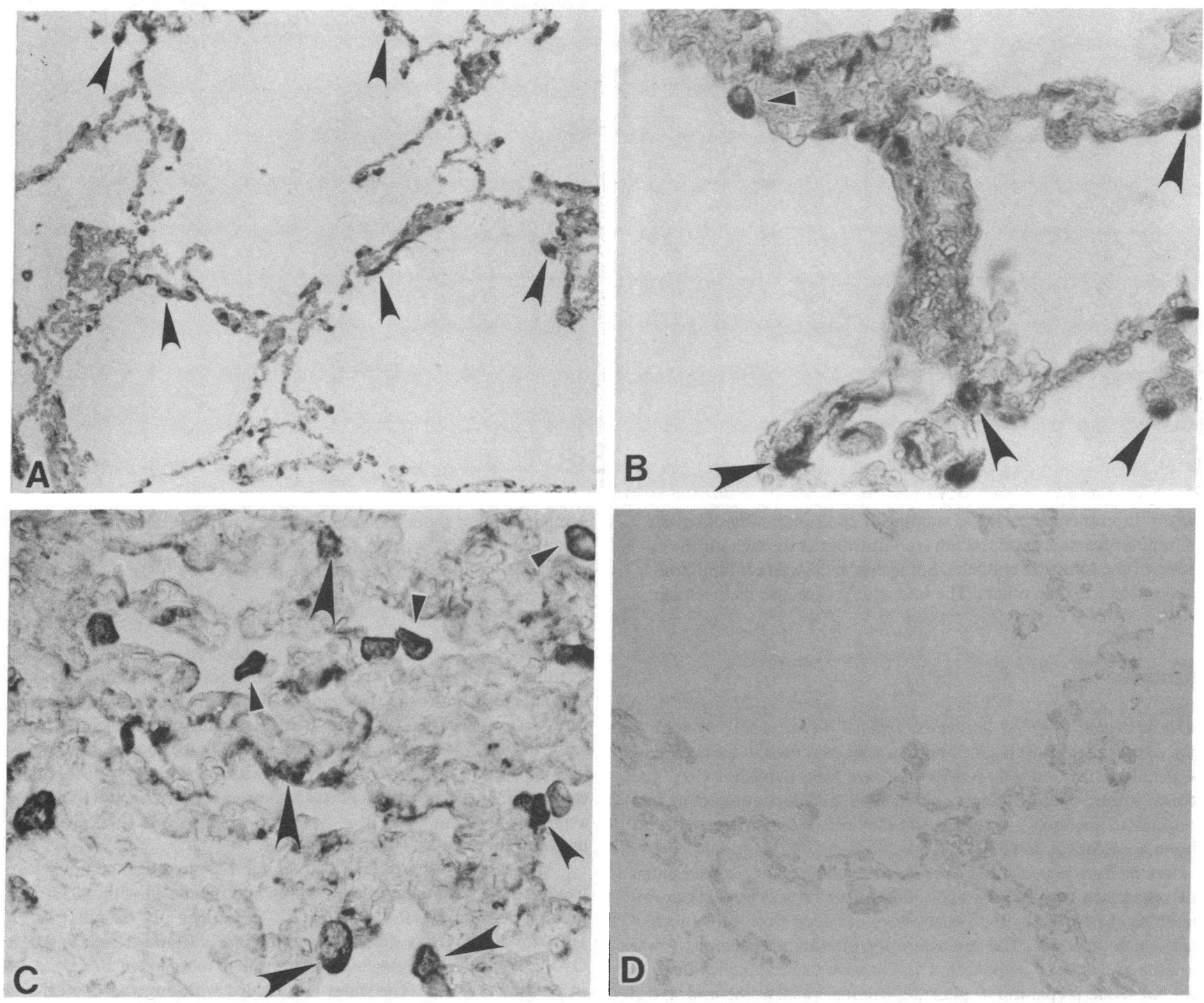

Figure 4. Immunolocalization of apoE in pulmonary tissues. $(A) \mathrm{A}$ low magnification of the lung tissue showing reaction products in some pneumocytes (arrowheads) of the alveolar system $(\times 300)$. (B) A higher magnification of the lung tissue showing several pneumocytes (black arrowheads) in the alveolar septa containing immunoreactive apoE. One type II round pneumocyte containing granular reaction products (small black and white arrowhead) is identified $(\times 1,500)$.

(C) A higher magnification taken from an atelectetic area reveals the presence of granular reaction products in the type II pneumocytes (black arrowheads) in the alveolar septa. Some free macrophages (small black and white arrowheads) in the alveolar spaces containing reaction products are also present in this field $(\times 1,500)$. (D) A control section stained with preimmune serum shows no specific reaction products $(\times 600)$.

Figure 5. Immunolocalization of apoE in the adrenal cortex. $(A) \mathrm{A}$ photomicrograph taken from an oblique section of the adrenal cortex. Reaction products are found mainly in the individual cells in the zona fasciculata $(Z F)$ and zona reticularis. In the cells that show positive staining (large arrowheads), granular reaction products are distributed throughout the cytoplasm. In the zona glomerulosa $(Z G)$, reaction products are associated mainly with the plasma membrane (small arrowheads), and no staining is visible in the cytoplasm $(\times 600)$. (B) A higher magnification taken from the zona fasciculata showing granular reaction products (arrowheads) distributed throughout the cytoplasm in the individual cells $(\times 1,400)$. $(C)$ A control section, stained with antiserum against apoE that has been pretreated with excess purified apoE shows no reaction product. $C$, capsule. $(\times 600)$.
Figure 6. Immunolocalization of apoE in the pancreas. $(A)$ A crosssection of a region of the pancreas showing reaction products only present in an islet of Langerhans. In the islet, the cells that contain immunoreactive apoE (arrowheads) are localized mostly in the peripheral region. In each of these cells, granular reaction products are evenly dispersed throughout the cytoplasm. The exocrine glandular structures are not stained $(\times 1,800)$. (B) A longitudinal section of an islet of Langerhans showing stained cells (arrowheads) localized mainly in the peripheral region. The central area contains clusters of negative cells $(\times 1,200)$. (C) A control section stained with preimmune serum shows no specific reaction products. I, islet of Langerhans $(\times 1,300)$. 

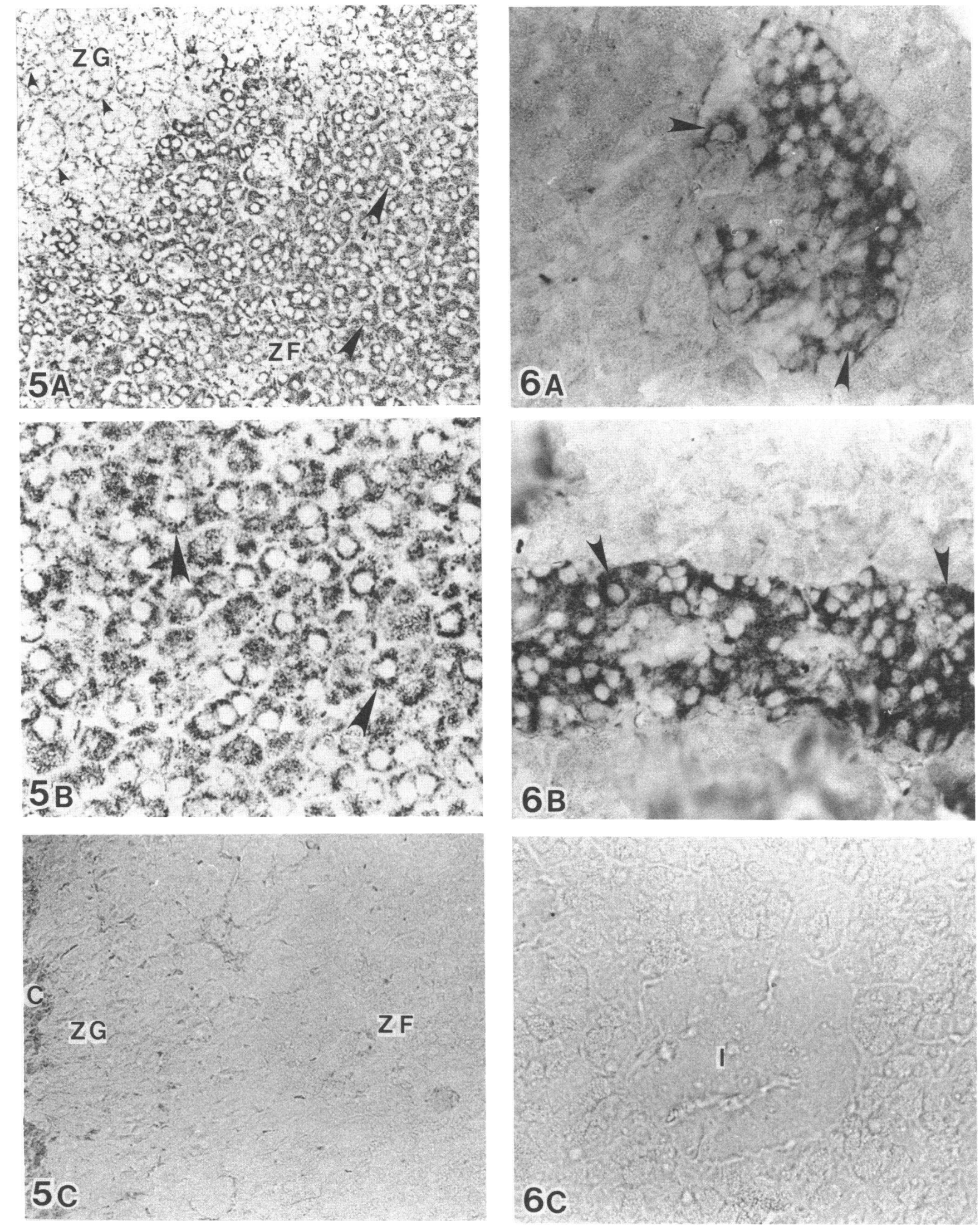

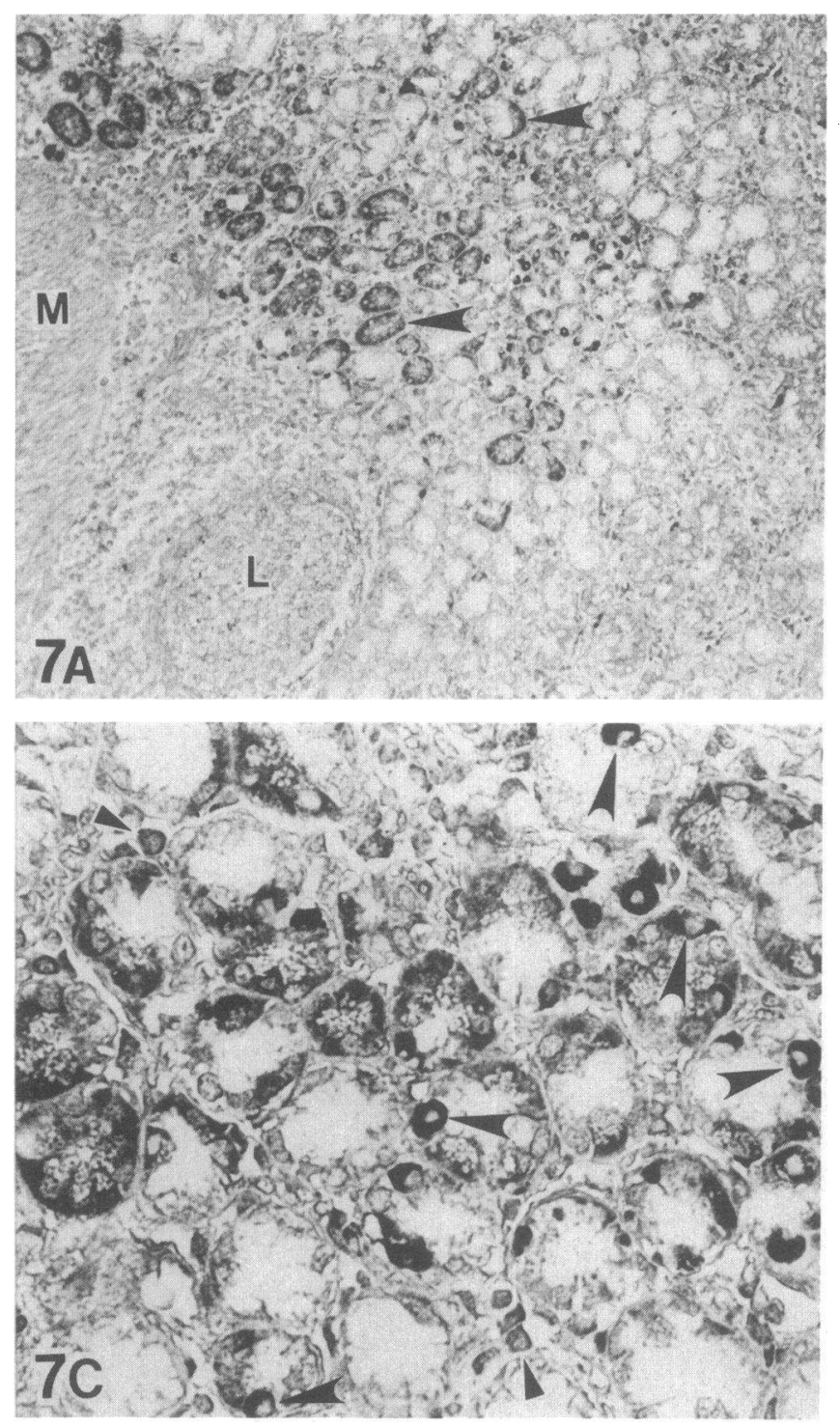

Figure 7. Immunolocalization of apoE in the stomach. $(A)$ Immunoreactive apoE is detected in some gastric glandular epithelia (arrowheads) adjacent to the muscularis mucosae $(M)$. The cells in the upper portions of the glandular epithelia show considerably weaker staining. L, lymphoid nodule $(\times 300)$. (B) A higher magnification of the gastric mucosa adjacent to the muscularis mucosae showing granular reaction products (black arrowheads) in selected glandular epithelia. In one glandular structure, some epithelial cells show intense immunostaining, whereas other cells remain unstained. In the lamina propria, some

in a reticulocyte lysate system as previously described (17). Immunoprecipitation of the products using the antiserum resulted in a single radioactive band on an SDS gel (Fig. $1 B$ ). It should be noted that in a previous study using the same antiserum, only a single in vitro product was precipitated following the translation of mRNA extracted from human liver as well as from several different baboon tissues, including liver, adrenal, spleen, brain, kidney, and intestine (17).

Immunohistochemistry. Using an antiserum specific for apoE, we have studied the distribution of immunoreactive apoE in various baboon tissues by the indirect immunoperoxidase
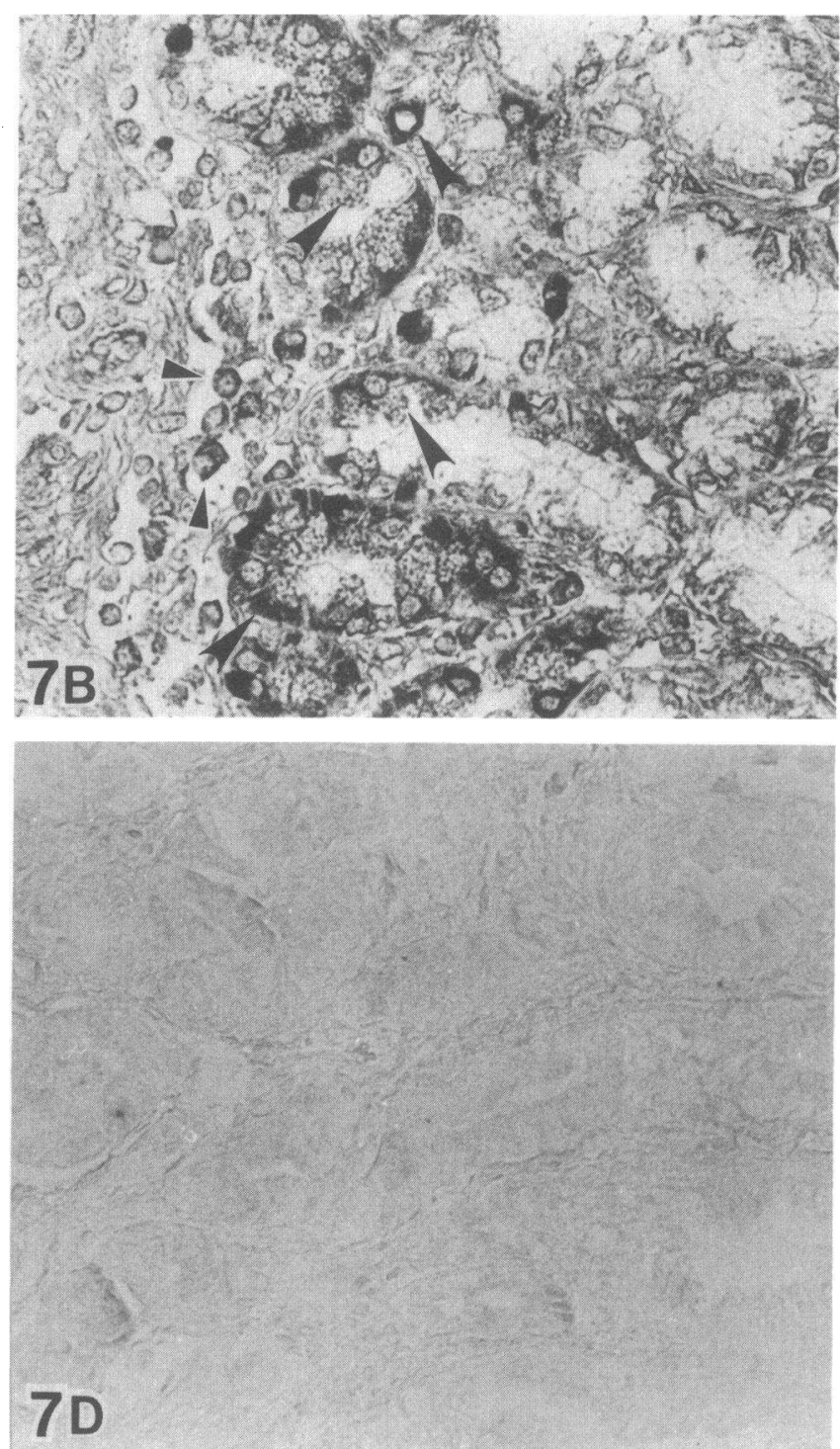

macrophages (small black and white arrowheads) in the interstitial space also contain reaction products $(\times 1,100)$. $(C)$ A photomicrograph of the middle portion of the gastric mucosa showing individual gastric epithelia cells (black arrowheads) that contain intensely stained reaction products. Some macrophages (small black and white arrowheads) in the interstitial spaces are also stained $(\times 1,100)$. (D) A control section stained with antiserum against ovalbumin shows no reaction products $(\times 1,400)$.

method using the $A B C$ (22) and peroxidase-antiperoxidase complex (PAP) (23) techniques. The following are descriptions of the immunohistolocalization of apoE in various baboon tissues. Many of the details of the localization are also described in the accompanying figure legends. In the blood vessels of the tissues studied, immunoreactive apoE was observed extracellularly on the luminal surface, and occasionally, small amounts of intracellular reaction product were also detected in the endothelial cells. Otherwise, immunoreactive apoE was confined to the specific cell types described below.

Cerebral cortex. We have studied the frontal lobe of the ba- 


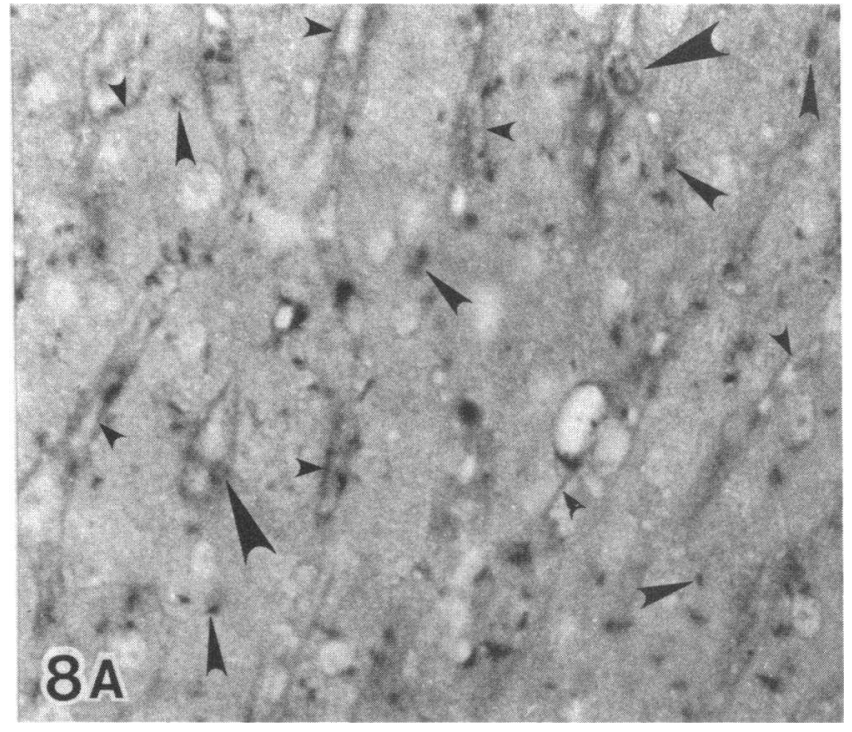

Figure 8. Immunolocalization of apoE in the liver. $(A)$ Individual hepatocytes contain a few granular reaction products (medium black arrowheads) only. The plasma membrane facing the sinusoidal space also shows some staining (small arrowheads). Some reaction products

boon cerebral cortex. Immunoreactive apoE reaction products were found in both white and gray matters (Fig. 2). The staining was confined to the glial cells, especially the astrocytes. In the white matter, some glial cell bodies and most of their processes contained reaction products (Fig. 2 B). Typical stained astrocytic processes ending on the small blood vessels were seen in places (Fig. $2 C$ ). A similar staining pattern was also found in the gray matter (Fig. $2 A$ ). However, none of the neurons contained any reaction products (Fig. $2 A$ ).

Thyroid gland. In the thyroid gland, variable amounts of granular reaction products were seen distributed throughout the cytoplasm of the follicular epithelia (Fig. $3 \mathrm{~A}$ ). The interstitial cells and matrices were not stained. The colloidal substance in the individual follicles contained no reaction products.

Lung. In the normal lung tissue, immunoreactive apoE was seen mainly in some pneumocytes lining the alveolar septa (Fig. $4 A$ ) arrowheads, and $4 B$, black arrowheads). Some type II pneumocytes containing granular reaction products (Fig. $4 B$, black and white arrowhead) were also observed. The septal capillary endothelia and fibrous tissue were not stained. In areas of atelectasis and septal fibrosis, some free macrophages (Fig. 4, black and white arrowheads) as well as type II pneumocytes (Fig. $4 C$, black arrowheads) were also stained. The bronchiolar epithelia and the small blood vessels were stained in occasional sections.

Adrenal gland. In the adrenal gland, the cortex showed intense staining, while the medulla showed moderate staining. In the adrenal cortex, cells in the zona fasciculata and zona reticularis contained numerous granular reaction products (Fig. 5, $A$ and $B$ ). In the zona glomerulosa, only the plasma membrane and not the cytoplasm, was stained (Fig. $5 \mathrm{~A}$, small arrowheads). The adrenal medullary cells contained moderate amounts of granular reaction products dispersed in the cytoplasm (data not shown).

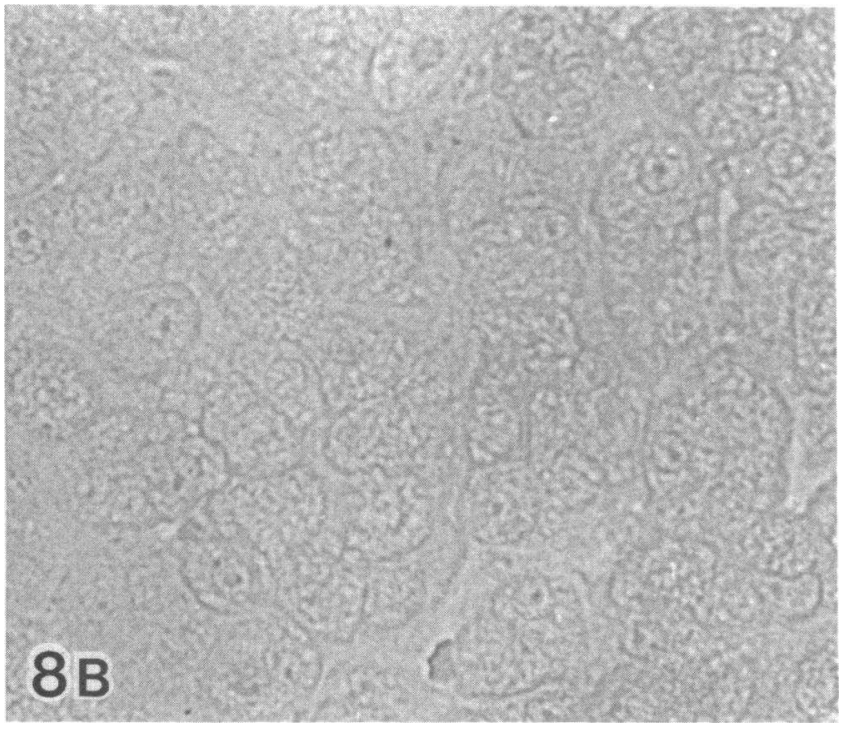

are detected in the Kupffer cells (large arrowheads) $(\times 1,400)$. (B) A control section stained with antiserum that has been preadsorbed with excess human apoE shows no reaction product $(\times 1,600)$.

Pancreas. In the pancreas, the exocrine glandular tissue showed no staining. However, all of the islets of Langerhans contained reaction products (Fig. 6). In each islet, the majority of the stained islet cells contained such products in the form of granules (Fig. 6, $A$ and $B$ ). These cells were located mainly in the peripheral regions of the islet. The central region of the islet was much less stained (Fig. 6 B).

Stomach. In the stomach, granular reaction products were generally confined to some of the gastric glandular epithelia (Fig. $7, A-C)$. The stained epithelia were mainly localized in the basal area of each gastric gland, though not all basal glandular epithelia were stained. Some epithelia contained more reaction products than others (Fig. 7, $B$ and $C$ ). The macrophages in the lamina propria and interstitial spaces were also stained (Fig. 7, $B$ and $C$, black and white arrowheads).

Liver. Essentially all hepatocytes contained immunoreactive products on immunostaining. These products were in the form of cytoplasmic granules (Fig. $8 \mathrm{~A}$, large black arrowhead). Each hepatocyte contained only a limited number of such granules. The plasma membrane of the hepatocyte facing the sinusoid was also stained (Fig. $8 A$, small black arrowheads). Most of the Kupffer cells contained some reaction products (Fig. $8 \mathrm{~A}$, medium black arrowheads). In the portal area, the bile duct epithelia and the blood vessels occasionally showed very weak immunostaining.

Kidney. In the kidney, the epithelia in most of the proximal convoluted tubules (Fig. $9 \mathrm{~A}$ ), and in some of the distal convoluted tubules (Fig. 9, $B$ and $C$ ) contained cytoplasmic granular reaction products. The loop of Henle and the collecting tubules were rarely stained. The glomeruli and small renal vessels occasionally showed weak staining. In the proximal convoluted tubular epithelia, the granules were unevenly distributed, and in most cases, were more prominent near the brush border (Fig. 9, $A$ and $C$, larger arrowheads). In the parts of the distal con- 

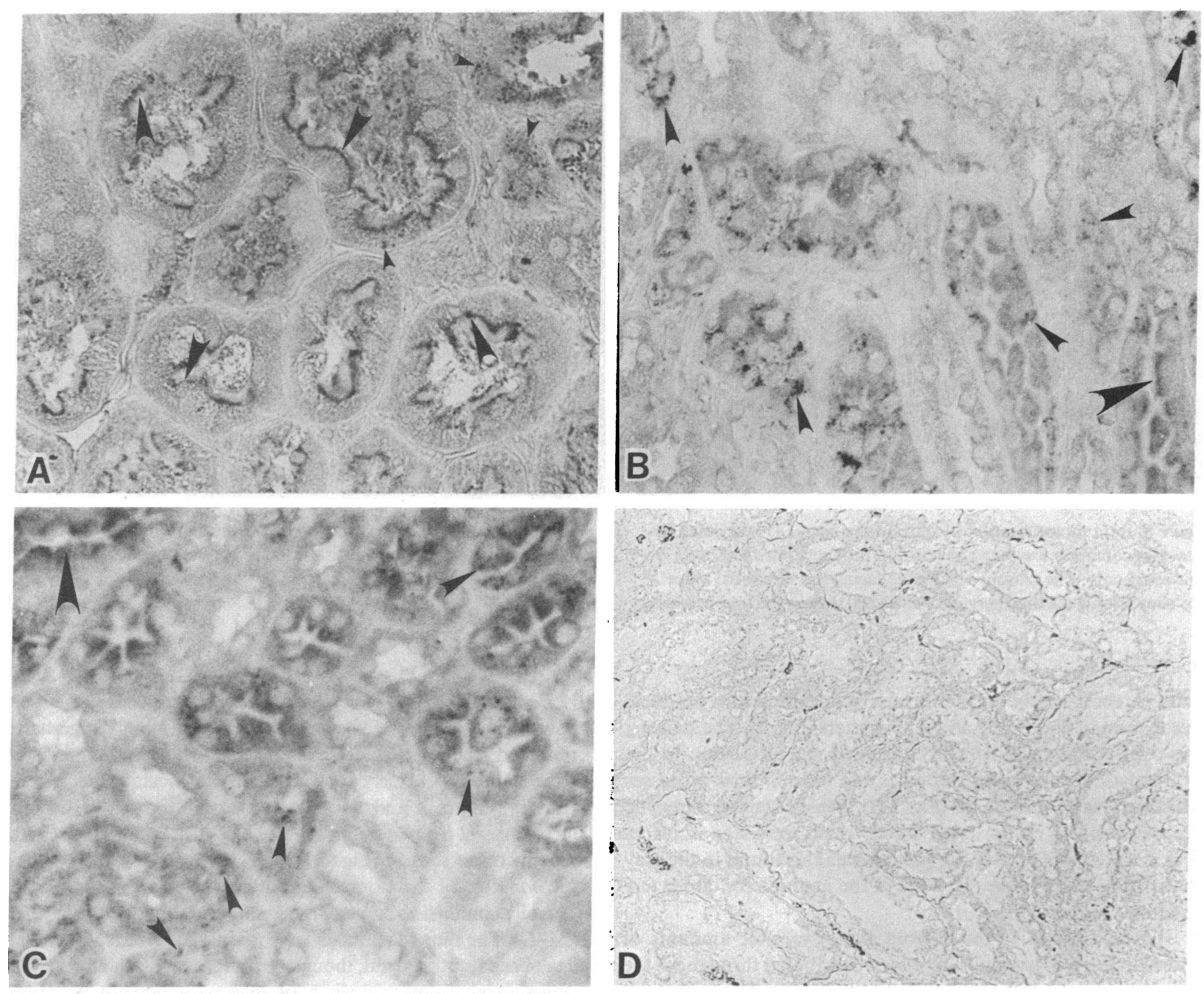

Figure 9. Immunolocalization of apoE in the renal cortex. $(A)$ Most of the proximal convoluted tubular epithelia show immunostaining. The immunoreactive apoE is concentrated mainly in the brush border area (large arrowheads). Sporadic stained granules are also present in the other parts of the cytoplasm (small arrowhead). The basement membrane is not stained $(\times 1,700)$. ( $B$ and $C$ ) In the distal convoluted tu-

voluted tubular epithelia that showed positive staining for apoE, the immunoreactive granules were evenly dispersed in the whole cytoplasm (Fig. 9, $B$ and $C$, small arrowheads).

Spleen and lymph nodes. In the spleen, granular reaction products were observed exclusively in macrophages (histiocytes) in the lymphoid follicles as well as in the nonfollicular regions (Fig. 10, $A$ and $B$ ). Similarly, in the lymph node, granular reaction products were localized in the cytoplasm of macrophages (Fig. $11, A$ and $B$ ). In each organ, the surface of some lymphoid cells also showed weak staining (Figs. $10 \mathrm{~B}, 11 \mathrm{~B}$, small black arrowheads), but no intracellular granular staining was found in these cells.

Ovary. In the ovary, only the follicles showed immunoreactive apoE. The stroma were entirely negative. In the primordial

bules, granular reaction products are present in somewhat fewer tubular epithelia (small arrowheads). The epithelia of the loop of Henle are rarely stained. Large arrowheads mark the staining close to the brush border $(B, \times 1,300 ; C, \times 1,200)$. (D) A control section stained with preimmune serum shows no reaction products $(\times 600)$.

follicle (Fig. $12 \mathrm{~A}$ ), growing follicles, and mature follicles, the ovum (oocyte) contained diffuse reaction products in the cytoplasm (Fig. 12, $A$ and $B$ ). The zona pellucida of the ovum did not contain any immunoreactive apoE (Fig. $12 \mathrm{~B}$ ), while the foot processes of the follicular cells in the corona radiata attached on the zona pellucida were intensely stained. Most of the follicular epithelia in the individual follicles showed reaction products associated with their plasma membranes (Fig. $12 \mathrm{C}$ ).

Control sections. Control sections of each tissue were stained with $(a)$ preimmune serum; $(b)$ antiserum against an unrelated protein (chick ovalbumin); or (c) anti-apoE serum preadsorbed with purified human apoE. None of these sections showed any visible reaction products. 

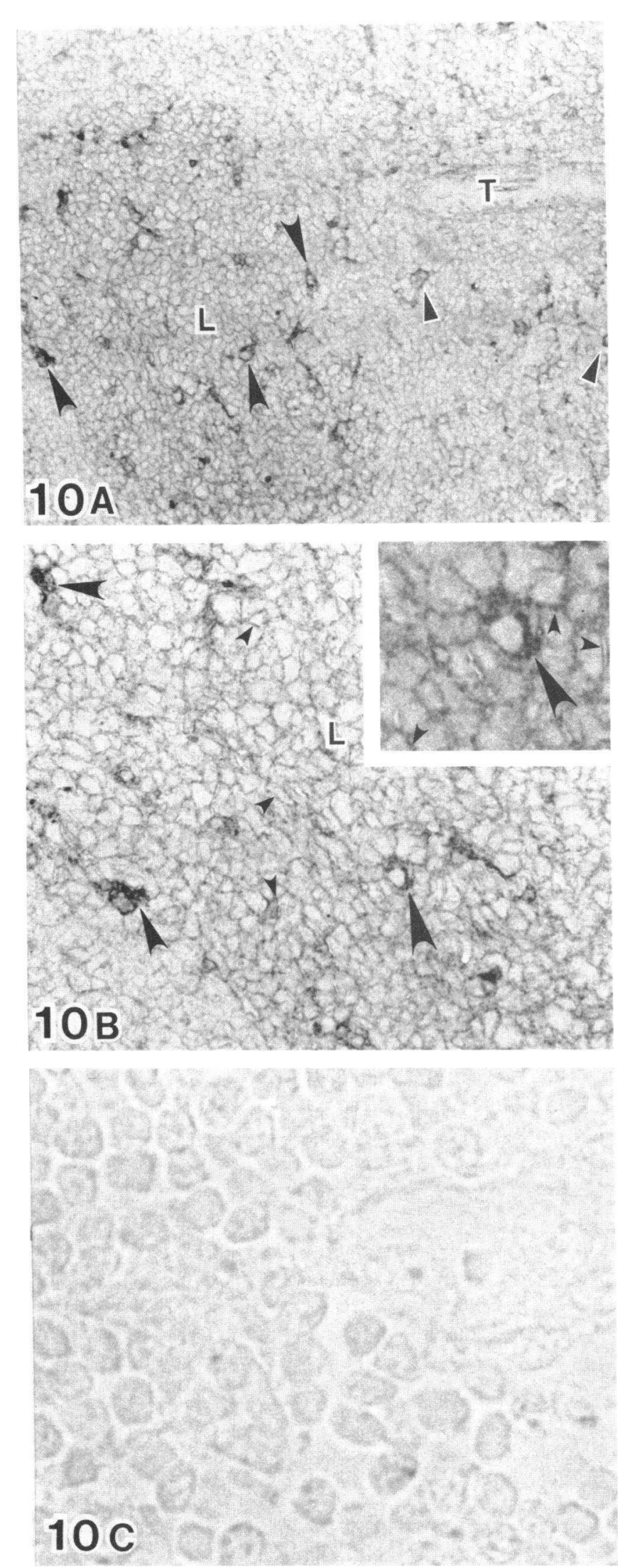

Figure 10. Immunolocalization of apoE in the spleen. $(A)$ Granular reaction products are present in the histiocytic macrophages in both the white pulp (black arrowheads) and the red pulp (small black and white

\section{Discussion}

Using the avidin-biotin peroxidase complex indirect immunocytochemical method (22) and an antiserum against human apoE, we found the presence of apoE immunoreactive product in the following baboon organs, cerebral cortex (frontal lobe), thyroid, lung, liver, adrenal, kidney, spleen, pancreas, ovary, lymph node, and stomach. The distribution of the stained cells in each organ is unique and the staining patterns in the immunoreactive cells from each organ are also different from each other. We have made essentially identical observations in the organs of the rhesus monkey (data not shown).

The possibility that we are detecting a protein that shows similar immunoreactivity to apoE (rather than authentic apoE) is highly unlikely. Many laboratories, including ours, have shown that hybridizable apoE mRNA of the expected size (by Northern blot analysis), as well as translatable apoE mRNA (demonstrated by in vitro translation) are found in the same tissues where we have detected immunoreactive apoE (12-18).

In the cerebral cortex of the frontal lobe, only glial cells but not neuronal cells were stained by the apoE antiserum. Reaction products were seen in the glial cell bodies and along their processes. Sometimes, the stained processes were found ending on the small blood vessels (Fig. $2 A$ and $C$ ). The staining in the cell bodies and their processes appeared to be homogeneously distributed. However, under light microscopic observation, we could not distinguish between the following two possibilities: $(a)$ that the apparently homogeneous staining was caused by the presence of numerous closely spaced reaction product-containing vesicles; or $(b)$ that it was the result of immunoreactive apoE occurring free in the cytoplasm of the cell. Our findings support the previous biochemical studies indicating that the cerebral cortex synthesized apoE $(13,15-18)$. Furthermore, they indicate that the cerebral glial cells are the sites of synthesis of this protein. While this study was in progress, Boyles et al. (24) presented a detailed analysis of the distribution of immunoreactive apoE in the central and peripheral nervous system in the rat and the mouse. Our observations in the baboon (and the rhesus monkey) generally agree with their findings. ApoE appears to be a widely distributed cellular protein in the mammalian nervous system.

In the various organs we have studied, the distribution and pattern of immunoreactive apoE in each cell type are unique. Granular reaction products, suggestive of apoE-containing secretory vesicles, were found in the thyroid follicular epithelia, alveolar type II pneumocytes, hepatocytes, the zona fasciculata

arrowheads). The trabeculae (T) and their vascular components are not stained, but the cell surfaces of some lymphocytes show weak staining. L, lymphoid nodule $(\times 600)$. $(B)$ A higher magnification taken from $(A)$. In this area, the reaction products are better demonstrated in some macrophages (large and medium arrowheads) and on the surface of some lymphocytes (small arrowheads). L, lymphoid nodule $(\times 1,300)$. (Inset) A higher magnification taken from the area marked by the large arrowhead of (B). Peroxidase reaction product is present in the cytoplasm of a macrophage (large arrowhead) and on the surfaces of lymphoid cells (small arrowheads) $(\times 2,800)$. The surface immunostaining is much more readily discerned in the original slide. $(C)$ A control section stained with preimmune serum shows no reaction product. $(\times 2,500)$. 

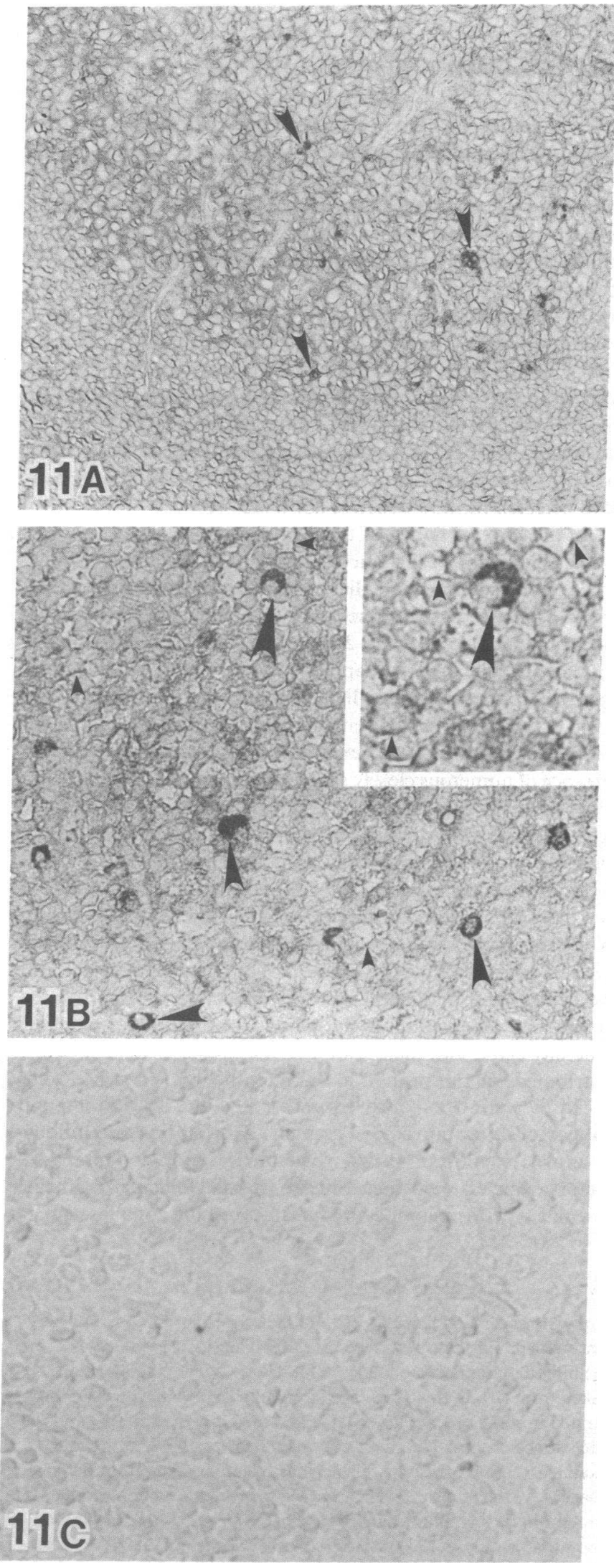

Figure 11. Immunolocalization of apoE in a mesenteric lymph node. $(A)$ Reaction products are detected in the histiocytic macrophages (arrowheads) and on the surface of some of the lymphocytes $(\times 800)$. $(B)$ and zona reticularis of the adrenal cortex, adrenal medullary cells, renal tubular epithelia, pancreatic islet cells, splenic macrophages, lymph node macrophages, and gastric glandular epithelia. The presence of secretory granules in these different cell types suggests that they synthesize apoE. Indeed, previous studies on tissue slices and organ cultures in vitro indicate that many of these organs synthesize apoE (10-18). The presence of apoE mRNA was also confirmed by in vitro translation and by nucleic acid hybridization in these tissues $(13,15-18)$. The granular nature of the immunoreactive apoE suggests that the protein might be secreted from these various cell types. While there are experiments which demonstrate that such is the case in the liver cells $(7,8,12)$, direct evidence for this process in the other organs and tissues must await further biochemical and physiological studies.

In other cell types, immunoreactive apoE was found also or mainly associated with the plasma membranes. These include the hepatocytes, the adrenal cortical epithelia in the zona glomerulosa, the follicular cells in the ovary and the parathyroid epithelia (data not shown). Furthermore, some lymphocytes in the spleen and lymph node also showed weak staining. Such a distribution suggests that except for the hepatocytes (which also contain intracellular apoE), the presence of reaction products on the cell membrane of many of these cells might be the result of apoE bound to the membrane of these cells, and the cells might not be the source of the protein.

One tissue that contained a unique distribution of reaction products was the ovum. The immunostaining was quite homogeneous throughout the cytoplasm of the ovum. In contrast, the zona pellucida contained no detectable reaction products. This observation suggests that the ovum may synthesize apoE which might serve an intracellular function. The possibility that the protein has been taken up and internalized from an exogenous source cannot be excluded by this study. Our observations in this tissue should be interpreted in the light of the study of Driscoll et al. (25) that in the rat, the ovarian granulosa cells synthesize apoE, and the synthesis of this protein in these cells appears to be regulated by follicle-stimulating hormone.

The stained cells in the gastric mucosa was seen mostly in the basal gastric glandular region. It is not clear whether these cells belong to acid-producing cells or other cell types. The function of apoE in these cells is unclear. The pattern and distribution of the protein suggest that apoE may be secreted into the gastric lumen.

In the pancreas, only endocrine cells were stained and most stained cells were in the peripheral regions of the islets of Langerhans. The cells in the central region were generally much less stained. The granular nature of the immunoreactive apoE in the islet cells suggests that the protein may be destined for se-

\footnotetext{
A higher magnification taken from one lymphoid nodule shows the presence of granular reaction products in the histiocytic macrophages (large and medium arrowheads). Weak staining on the surfaces of some of the lymphocytes (small arrowheads) is also shown $(\times 1,400)$. (Inset) A higher magnification taken from the area marked by the large arrowhead in (B). Peroxidase reaction product is present inside a macrophage (large arrowhead) and on the surfaces of lymphoid cells (small arrowheads) $(\times 2,700)$. The immunostaining on the cell surfaces is considerably more distinct on the original slide. $(C)$ A control section of a lymph node stained with preimmune serum shows no specific staining $(\times 1,400)$.
} 

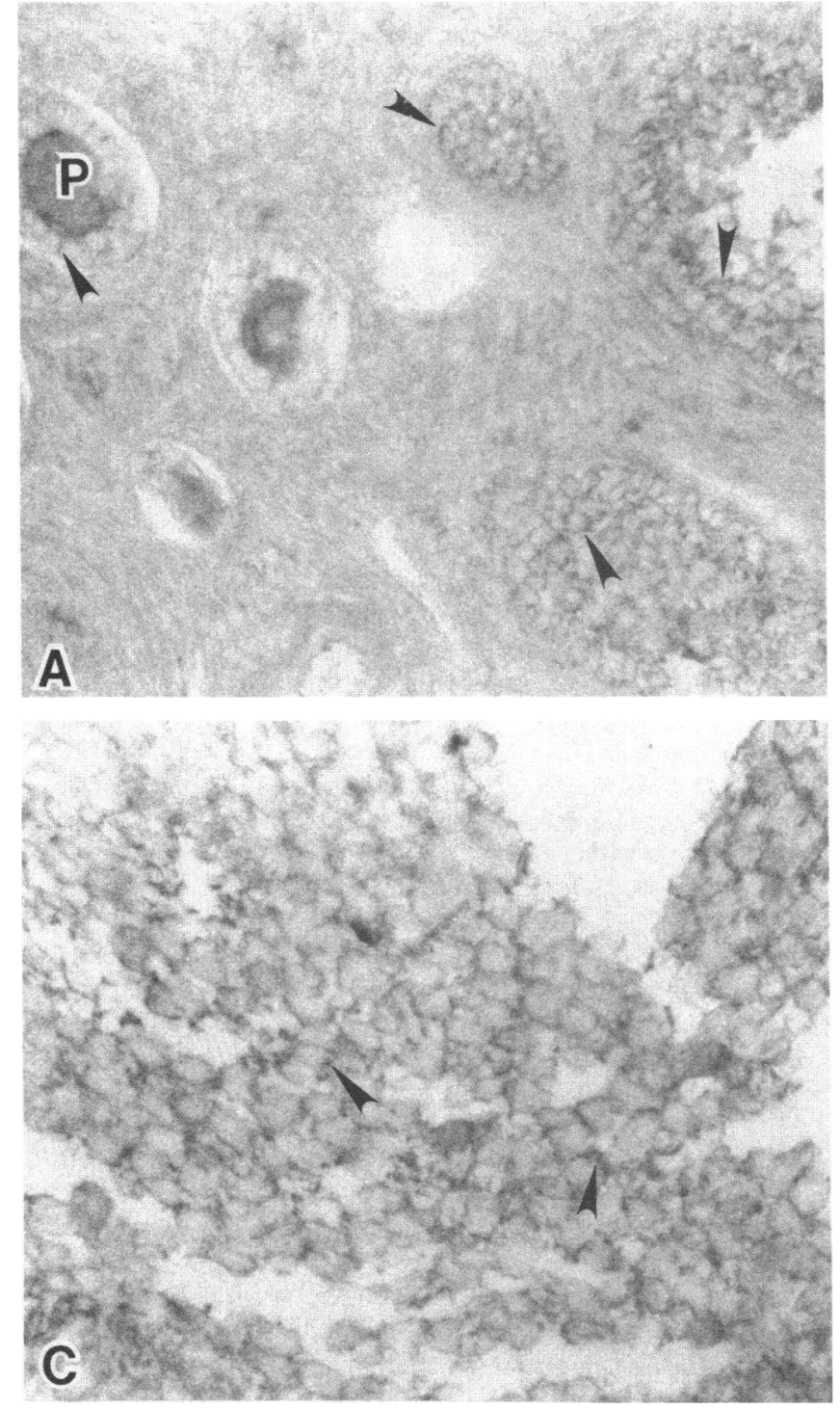

Figure 12. Immunolocalization of apoE in the ovary. $(A)$ Reaction products are mainly associated with the plasma membranes of all the follicular cells (black arrowheads) in each Graafian follicle, including a primordial follicle $(P)$, some growing and some mature follicles. The cytoplasm of the ovum is diffusely stained. The stroma is unstained $(\times 800)$. (B) A growing follicle showing reaction products detected as a homogeneous staining involving the entire cytoplasm of the ovum $(O)$. The zona pellucida is unstained. The foot processes of the follicu-

cretion. This study does not allow us to identify the type of islet cells which synthesize apoE. Additional studies are required for a positive identification of these cells.

It is now generally accepted that there is widespread extrahepatic synthesis of apoE in the mammal (10-18). For example, Newman et al. (16) estimated that in two non-human primates, Macaca fascicularis and Cercopithecus aethiops, 20-40\% of total body apoE mRNA is extrahepatic. These peripheral tissues thus have the potential to contribute a substantial fraction of plasma apoE. Previous studies performed on tissue extracts or organ cultures do not allow us to determine the cellular origin of the apoE mRNA. Our observations using immunohistochemical techniques provide information in this respect.
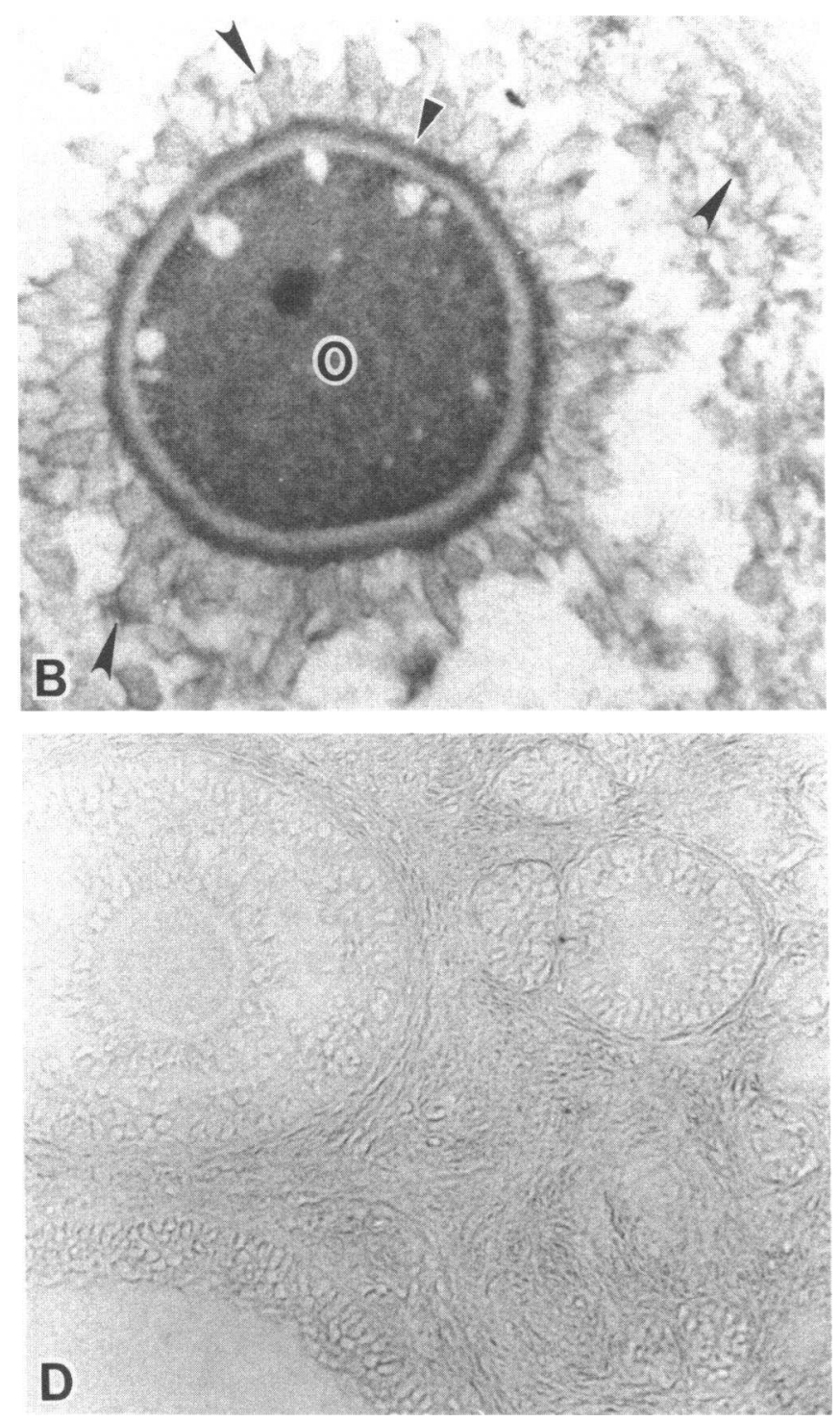

lar cells in the corona radiata (black and white arrowhead) are also heavily stained. The plasma membranes of the follicular cells show weak staining (large black arrowheads) $(\times 1,600)$. $(C)$ A higher magnification taken from part of a mature follicle showing reaction products mainly associated with the plasma membrane of the follicular cells (arrowheads) $(\times 1,400)$. (D) A control section stained with antiserum preadsorbed to purified apoE shows no specific staining $(\times 600)$.

The cellular distribution of apoE in various organs and tissues might provide a clue to the potentially very diverse functions of this protein. It is likely that apoE synthesized in the macrophages in the spleen, lymph node, lung tissues, as well as the liver (Kupffer cells) contribute to the plasma apoE and might be important in the context of reverse cholesterol transport as well as immunomodulation $(26,27)$. However, the peripheral production of apoE in other extrahepatic cells and tissues does not necessarily imply that the protein is secreted into the extracellular space and/or makes its way to the circulation. Certainly, apoE produced in the brain must be largely confined to the central nervous system because of the presence of the blood-brain barrier. The mode of distribution of apoE in other organs also indicates some 
alternative functions for the protein. For example, the demonstration of apoE in pancreatic islets may be indicative of some local endocrine or paracrine function. Similarly, the presence of the protein in other endocrine tissues such as the adrenal cortex and medulla, the thyroid gland and the ovary also suggests that apoE might contribute, in some way, to the local hormonal homeostasis in these organs. The presence of immunoreactive apoE in other organs such as the tubular epithelia of the kidney and the glandular epithelia of the stomach also suggests potentially important functions of apoE in these highly differentiated tissues. The fact that a single patient with plasma apoE deficiency has been described $(28,29)$ should not negate these other potential roles for this protein, since such functions may be assumed by other proteins. A similar situation is noted in the case of analbuminemia where the absence of a major physiological serum protein is consistent with relatively normal health (3032). Additional investigations using isolated organs, tissues, and cells are needed to further define the physiological roles of apoE, a widely distributed cellular protein.

\section{Acknowledgments}

We thank Dr. J. W. Liu for excellent technical assistance, and Dr. William A. Bradley for supplying the anti-apoE serum. Some of the baboon tissues were kindly provided by Drs. Glen E. Mott and Henry McGill of the Southwest Foundation for Biomedical Research, San Antonio, TX.

This study was supported in part by National Institutes of Health grants CA-36934, NS-20978, and HL-27341.

\section{References}

1. Mahley, R. W., T. L. Innerarity, S. C. Rall, Jr., and K. H. Weisgraber. 1984. Plasma lipoproteins: apolipoprotein structure and function. J. Lipid Res. 25:1277-1294.

2. Brown, M. S., and J. L. Goldstein. 1983. Lipoprotein receptors in the liver. Control signals for plasma cholesterol traffic. J. Clin. Invest. 72:743-747.

3. Rall, S. C., Jr., K. H. Weisgraber, T. L. Innerarity, and R. W. Mahley. 1982. Human apolipoprotein E. The complete amino acid sequence. J. Biol. Chem. 257:4171-4178.

4. Mahley, R. W., and T. L. Innerarity. 1983. Lipoprotein receptors and cholesterol homeostasis. Biochim. Biophys. Acta. 737:197-222.

5. Hui, D. Y., T. L. Innerarity, and R. W. Mahley. 1981. Lipoprotein binding to canine hepatic membranes: metabolically distinct apoE and apoB receptors. J. Biol. Chem. 256:5646-5655.

6. Sherrill, B. C., T. L. Innerarity, and R. W. Mahley. 1980. Rapid hepatic clearance of the canine lipoproteins containing only the $\mathrm{E}$ apoprotein by high affinity receptor. J. Biol. Chem. 255:1804-1807.

7. Wu, A. L., and H. G. Windmueller. 1979. Relative contributions by liver and intestine to individual plasma apolipoproteins in the rat. $J$. Biol. Chem. 254:7316-7322.

8. Lin-Lee, Y. C., Y. Tanaka, C. T. Lin, and L. Chan. 1981. Effects on an atherogenic diet on apolipoprotein $\mathrm{E}$ biosynthesis in the rat. Biochemistry. 20:6474-6480.

9. Tanaka, Y., Y. C. Lin-Lee, M. H. Lin-Su, and L. Chan. 1982. Intestinal biosynthesis of apolipoproteins in the rat: apoE and apoA-I mRNA translation and regulation. Metab. Clin. Exp. 31:861-865.

10. Basu, S. K., M. S. Brown, Y. K. Ho, R. J. Havel, and J. L. Goldstein. 1981. Mouse macrophages synthesize and secrete a protein resembling apolipoprotein E. Proc. Natl. Acad. Sci. USA. 78:7545-7549.

11. Basu, S. K., Y. K. Ho, M. S. Brown, D. W. Bilheimer, R. G. W. Henderson, and J. L. Goldstein. 1982. Biochemical and genetic studies of the apoprotein $\mathrm{E}$ secreted by mouse macrophages and human monocytes. J. Biol. Chem. 257:9877-9795.

12. Blue, M.-L., D. L. Williams, S. Zucker, S. A. Khan, and C. B. Blum. 1983. Apolipoprotein E synthesis in human kidney, adrenal gland, and liver. Proc. Natl. Acad. Sci. USA. 80:283-287.
13. Elshourbagy, N. S., W. S. Liao, R. W. Mahley, and J. M. Taylor. 1984. Apolipoprotein E mRNA is abundant in the brain and adrenals, as well as in the liver, and is present in other peripheral tissues of rats and marmosets. Proc. Natl. Acad. Sci. USA. 82:203-207.

14. Driscoll, D. M., and G. S. Getz. 1984. Extrahepatic synthesis of apolipoprotein E. J. Lipid Res. 25:1368-1379.

15. Williams, D. L., P. A. Dawson, T. C. Newman, and L. L. Rudel. 1985. Apolipoprotein $E$ synthesis in peripheral tissues of non-human primates. J. Biol. Chem. 260:2444-2451.

16. Newman, T. C., P. A. Dawson, L. L. Rudel, and D. L. Williams. 1985. Quantitation of apolipoprotein $\mathrm{E}$ mRNA in the liver and peripheral tissues of nonhuman primates. J. Biol. Chem. 260:2452-2457.

17. Lin-Lee, Y. C., F. T. Kao, P. Cheung, and L. Chan. 1985. Apolipoprotein E gene mapping and expression localization of the structural gene to human chromosome 19 and expression of apoE mRNA in lipoprotein and non-lipoprotein producing tissues. Biochemistry. 24:37513756.

18. Zannis, V. I., F. S. Cole, C. L. Jackson, D. M. Kurnit, and S. K. Karathanasis. 1985. Distribution of apolipoprotein A-I, C-III, and E mRNA in fetal human tissues. Time-dependent induction of apolipoprotein E mRNA by cultures of human monocyte macrophages. Biochemistry. 24:4450-4455.

19. Gianturco, S. H., A. M. Gotto, Jr., S. L. C. Hwang, J. B. Karlin, A. H. Y. Lin, S. C. Prasad, and W. A. Bradley. 1983. Apolipoprotein E mediates uptake of $S_{\mathrm{f}} 100-400$ hypertriglyceridemic very low density lipoproteins by the low density lipoprotein receptor pathway in normal human fibroblasts. J. Biol. Chem. 258:4526-4533.

20. Lin, C. T., and L. H. Chen. 1983. Production and characterization of an antibody to cytosolic aspartate aminotransferase and immunolocalization of the enzyme in rat organs. Lab. Invest. 48:718-725.

21. Lin, C. T., and L. Chan. 1986. Morphological localization of apolipoproteins and their mRNA by immunocytochemistry and in situ nucleic acid hybridization. Methods Enzymol. 129:297-319.

22. Hsu, S., L. Raine, and H. Fanger. 1981. Use of avidin-biotin peroxidase complex $(\mathrm{ABC})$ in immunoperoxidase techniques. J. Histochem. Cytochem. 29:577-580.

23. Sternberger, L. A. 1974. Immunocytochemistry. Prentice-Hall, Inc., Englewood Cliffs, NJ. 129 pp.

24. Boyles, J. K., R. E. Pitas, E. Wilson, R. W. Mahley, and J. M. Taylor. 1985. Apolipoprotein E associated with astrocytic glia of the central nervous system and with nonmyelinating glia of the peripheral nervous system. J. Clin. Invest. 76:1501-1513.

25. Driscoll, D. M., J. R. Schreiber, V. M. Schmit, and G. S. Getz. 1985. Regulation of apolipoprotein $E$ synthesis in rat ovarian granulosa cells. J. Biol. Chem. 260:9031-9038.

26. Hui, D. Y., J. A. K. Harmony, T. L. Innerarity, and R. W. Mahley. 1980. Immunoregulatory plasma lipoproteins. Role of apoprotein E and apoprotein B. J. Biol. Chem. 255:11775-11781.

27. Avila, E. M., G. Holdsworth, M. Sasaki, R. L. Jackson, and J. A. Harmony. 1982. Apoprotein E suppresses phytohemagglutininactivated phospholipid turnover in peripheral blood mononuclear cells. J. Biol. Chem. 257:5900-5909.

28. Ghiselli, G., E. J. Schaefer, P. Gascon, and H. B. Brewer, Jr. 1981. Type III hyperlipoproteinemia associated with apolipoprotein E deficiency. Science (Wash. DC). 214:1239-1241.

29. Zannis, V. I., J. M. Ordovas, C. Cladaras, F. S. Cole, G. Forbes, and E. J. Schaefer. 1985. mRNA and apolipoprotein E synthesis abnormalities in peripheral blood monocyte macrophages in familial apolipoprotein E deficiency. J. Biol. Chem. 260:12891-12894.

30. Nagase, S., K. Shimamune, and S. Shumija. 1979. Albumindeficient rat mutant. Science (Wash. DC). 205:590-591.

31. Murray, J. C., C. M. Demopulos, R. M. Lawn, and A. C. Motulsky. 1983. Molecular genetics of human serum albumin: restriction enzyme fragment length polymorphisms and analbuminemia. Proc. Natl. Acad. Sci. USA. 80:5951-5955.

32. Dammaco, F., A. Miglietta, A. D'Addabbo, A. Fratello, R. Moschetta, and L. Bonomo. 1980. Analbuminemia: report of a case and review of the literature. Vox Sang. 39:153-161. 